\title{
Frequency of Ketoacidosis in Newly Diagnosed Type 1 Diabetic Children
}

\author{
Zahra Razavi
}

\section{Abstract}

Objectives: Diabetic ketoacidosis (DKA) is the leading cause of morbidity and mortality in children with type 1 diabetes mellitus (TIDM). Many patients with newly diagnosed type 1 diabetes present with DKA. The aim of this study is to determine the frequency and the clinical presentation of diabetic ketoacidosis at the diagnosis of type 1 diabetes mellitus in youths in hamadan, Western Province of Iran.

Methods: The Clinical and laboratory data of a total of 200 patients under 19 years of age with newly diagnosed type 1 diabetes mellitus between 1995-2005 were retrospectively reviewed. Statistical analysis was performed using SPSS 11.

Results: 48 (24\%)of the children were presented in a state of ketoacidosis. Sever form of DKA $(\mathrm{pH} \leq 7.2)$ was observed in $54.5 \%$ of patients. The mean age at diagnosis was $7.3 \pm 5.15$ years in DKA group and $8.59 \pm 3.07$ in non-DKA group $(p=0.22)$. $60.4 \%$ of patient with DKA were female whereas in the nonDKA group, $53.3 \%$ of patients were female, the difference was not significant $(p=0.38)$. The duration of symptoms before diagnosis was $14.84 \pm 8.19$ days in patients with DKA and $22.39 \pm 2.27$ in the non-DKA group, $(p=0.11)$. No significant difference was found between the age, sex and duration of the symptoms and occurance of DKA. Polydipsia (85.4) polyuria (83.3\%), weakness (68.8\%) and abdominal pain $(52.1 \%)$ were the most frequently notified symptoms among the patients. In two cases, diagnosis of DKA was preceded by as appendicitis and the patient underwent appendectomy.

Conclusion: Frequency of DKA at onset of type 1 diabetes mellitus was significant in the studied region. However, it was lower than other regions in Asia. Polydipsia, polyuria, fatigue and abdominal pain were the most common symptoms on presentation.

From the Department of Pediatric Endocrinology, Besat Hospital, Hamadan Iran.

Received: 21 Dec 2009

Accepted: 26 Feb 2010

Address correspondence and reprint request to Dr. Zabra Razavi, Department of Pediatric Endocrinology, Besat Hospital Hamadan Iran.

Email :Razavizabra@yahoo.com.au

Razavi Z. OMJ. 25, 114-117 (2010); doi:10.5001/omj.2010.31

\section{Introduction}

iabetic ketoacidosis is the leading cause of morbidity and mortality in diabetic children. It accounts for more than 100,000 hospital admissions and at least 4000 deaths per year in the US. ${ }^{1,2}$ In the year 2000, the International Society for Pediatric and Adolescent Diabetes (ISPAD) stated that even nowadays DKA is the most common cause of diabetes-related death in children. ${ }^{3-6}$ The mortality appears to be greatest among patients at first presentation. ${ }^{\text {? }}$

The frequencies of DKA ranges between $15-70 \%$ in Europe, Australia, and North America U.S. ${ }^{8,9}$ Approximately 30\% of newly -onset diabetic children present with ketoacidosis. ${ }^{10-13}$ The economical burden associated with DKA treatment is also significant. Maldonado showed that the average cost of treating one hospital admission for DKA was approximately $\$ 10,875.78$ in the USA. ${ }^{14,15}$ There is considerable variation in the prevalence of DKA at onset of diabetes mellitus in different countries. Diabetic ketoacidosis has been reported to be more common in developing countries. $^{8,9}$

This study aims to determine the frequency, and to describe the clinical characteristics of ketoacidosis at onset of childhood type 1 diabetes mellitus (T1DM) in Hamadan, Western Province of Iran. This study will also compare the findings with similar studies in particular those reported from Asia.

\section{Methods}

Hamadan with almost $1,700,000$ inhabitants is a North Western Province of Iran. Ekbatan is a tertiary-care referral teaching hospital in the capital city of Hamadan.

The inclusion criteria for the sample for this retrospective study included; age $<19$ years, all participants were diagnosed with type 1 diabetes mellitus and discharged with insulin treatment in Ekbatan hospital. Hospital records for all subjects were reviewed to study subjects who initially presented with DKA. Demographical data including age, gender, duration of symptoms, clinical features of the disease, presence and severity of DKA at diagnosis were collected. Specific initial laboratory data including blood glucose level and arterial blood gas were also recorded. The data was divided into four age groups: 0-5, 5-10, 10-15 and 15-20 yrs.

The diagnosis of T1DM was established according to the WHO criteria, DKA was defined by glucose $>250 \mathrm{mg} / \mathrm{dL}$, arterial $\mathrm{pH}<7.30$, blood bicarbonate $<15 \mathrm{mmol} / \mathrm{L}$ and ketonuria greater than $(2+)$ in dipstick urine test with recent positive history of polyuria, polydypsia, nocturia and weight loss. ${ }^{3}$

Severity of diabetic ketoacidosis (DKA) was defined by serum $\mathrm{pH}$ and categorized into three groups; mild as $7.2 \mathrm{pH}<7.3$, moderate as $7.1<\mathrm{pH}<7.2$ and severe as $\mathrm{pH}<7.1$. 
There were no identify cases of type 2 Diabetes Mellitus in this study. The exclusion criteria included any error in hospital records.

The study was conducted in accordance with The National Ethical Committee at the Ministry of Health and Medical Education of Iran. The Committee of ethics in research of Hamadan University of medical sciences, reviewed and approved the study in 2004.

Statistical data analysis was performed using SPSS 11. Associations between DKA and sex were evaluated using the Chi-squared test. Independent T-test was applied to compare the age and duration of symptoms before diagnosis in the DKA and the non-DKA groups. $P$-value less than 0.05 was defined as statistically significant.

\section{Results}

During this 5 year period, a total of 200 subjects were hospitalized in Ekbatan center with newly-onset T1DM. At diagnosis, approximately $48(24 \%)$ of the children presented with DKA (Fig. 1). Among all patients who fulfilled the inclusion criteria for DKA, $54.5 \%$ were in the severe group. The mean age at diagnosis was $7.3 \pm 5.15$ years. There was no significant correlation between age and the occurance of DKA $(p=0.22) .29$ patients with DKA were females. Although girls presented more frequently (60\%) with DKA than did boys (40\%), the difference was not significant $(p=0.38)$.

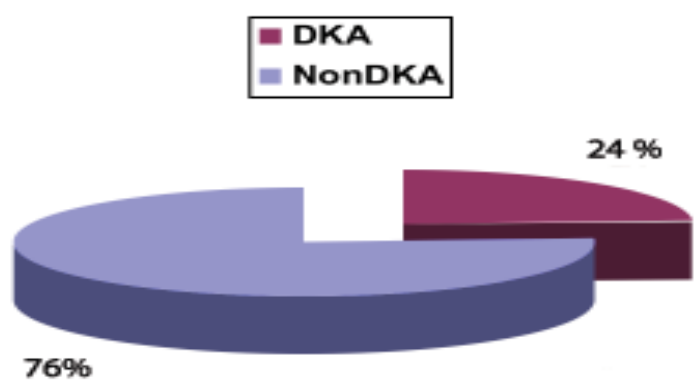

Figure 1: Frequency of DKA at the time of diagnosis of type 1 diabetes mellitus

The mean duration of symptoms before diagnosis was $14.84 \pm 8.19$ days in patients with DKA (ranging from 6 to 40 days) and $22.39 \pm 2.27$ (ranging from 6-120 days) in patients without DKA, the difference was not statistically significant $(p=0.11)$. There was also no significant difference between the age, sex and duration of the symptoms before diagnosis and DKA. The Patient characteristics with and without DKA are summarized in Table 1. The majority of the study patients were aged between 5-10 years in both groups (Fig. 2). Some of the signs and symptoms were similar in both groups except for abdominal pain and impared consciousness, which were not associated with the nonDKA groups (Table 2). Comparisons of clinical symptoms before diagnosis of patients with DKA and those without are shown in Table 2.

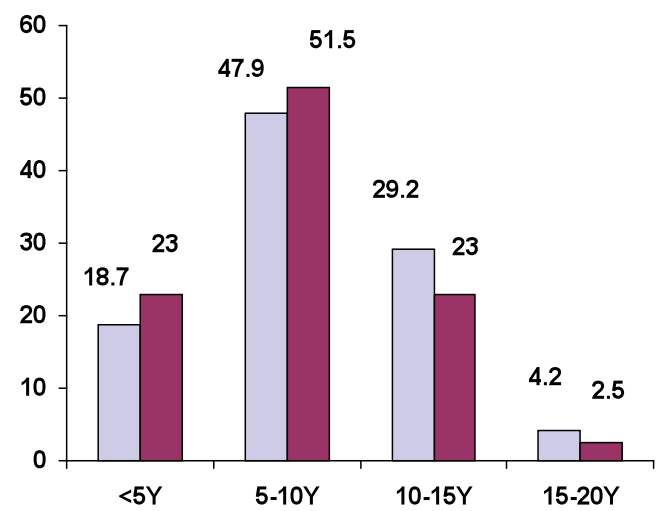

Figure 2: Comparison of age group in DKA and non DKA patients

Table 1: Clinical characteristics between subjects with or without DKA at presentation of T1 DM

\begin{tabular}{l|lll|}
\hline & $\begin{array}{l}\text { DKA } \\
\text { N=48 }\end{array}$ & $\begin{array}{l}\text { Non DKA } \\
\text { N=152 }\end{array}$ & p value \\
\hline Frequency & $24 \%$ & $76 \%$ & \\
Age(years) & $7.3 \pm 5.15$ & $8.59 \pm 3.07$ & $p=0.22$ \\
Gender & $29(60 \%)$ & $81(53.3 \%)$ & $p=0.38$ \\
Duration of symptoms (days) & $14.84 \pm 8.19$ & $22.39 \pm 2.27$ & $p=0.11$ \\
Mean serum glucose (mg/dl) & $429.9 \pm 170.2$ & $392.6 \pm 136.3$ & \\
5-10years & $47.9 \%$ & $51.5 \%$ & \\
\hline
\end{tabular}

Table 2: Comparsions of the Clinical symptoms in patients with or without DKA at onset of T1 DM(N=200)

\begin{tabular}{llllll}
\hline & \multicolumn{3}{c}{ DKA N=48 } & \multicolumn{2}{c}{ Non DKA N=152 } \\
& Number & Percent & Number & Percent \\
\hline Polyuria & 41 & 85.4 & 143 & 94.5 \\
Polydipsia & 40 & 83.3 & 142 & 93.5 \\
Fatigue & 33 & 68.8 & 64 & 42 \\
Nausea & 16 & 33.3 & 39 & 26 \\
Polyphagia & 23 & 47.9 & 39 & 26 \\
Abdominal pain & 25 & 52.1 & 0 & 0 \\
Impaired consciousness & 23 & 47.9 & 0 & 0
\end{tabular}


No deaths were recorded among the study population. The findings from this study also indicated that diagnosis was missed in two cases of DKA (the patients had been suspected of having appendicitis and underwent laparatomy).

\section{Discussion}

This is the first report to determine the frequency and clinical presentation of diabetic Ketoacidosis at onset of T1DM in this region of Iran.

The major finding from this study was that a approximately one-quarter of the children presented with ketoacidosis at the time of initial diagnosis in which most of them were in the severe group. This finding is consistent with previous studies reported by Neu et al. in Germany (26.3\%), Rewers in the USA (25.5\%) and Jasiński in Poland (25\%). $3,11,16$

However, in Iran and in Asia, frequency of DKA was lower than other previous studies which have reported from Asia. Alvi showed that young Asian children in Birmingham had an eightfold increased risk of presenting with DKA as did non-Asian children. ${ }^{17}$ In a study by Habib, 55.3\% and Al Magamsi $55.2 \%$ of diabetic children presented with ketoacidosis at diagnosis in Saudia Arabia ${ }^{18.19}$ Similarly, 65\% of the 304 patients in Taiwan and $49 \%$ of newly diagnosed diabetic children in Kuwait presented with diabetic ketoacidosis. ${ }^{20,21}$ The lower incidence of DKA in the current study compared with other Asian populations may be due to geographical and racial variations or environmental factors. It may also be due to better access to medical advice and early diagnosis of diabetes by physicians. The following interpretation most likely, hence there is urgent need for treatment of the newly diagnosed diabetic children. This is a view also strongly considered by their parents.

In agreement with other studies polydipsia, polyuria, weakness, and abdominal pain were the most frequently reported clinical symptoms at diagnosis. Similar results have been reported in studies by Al Magamsi and lofs ${ }_{*}{ }^{19,22}$

In terms of the duration of symptoms before diagnosis, the DKA group exhibited shorter duration of symptoms compared with the non-DKA groups. It would seem that the course of the disease was particularly progressive and fulminant as others have previously assumed in their studies, ${ }^{3,23}$

This study revealed that the majority of cases were admitted to hospital in serious states of ketoacidosis. However, recovery was well without complications, hence no deaths were reported as a result of ketoacidosis. It is interesting to note that the hospital was the referral center, therefore it may be due to increased medical awareness in appropriate and efficient management of patients with DKA. The hypothesis supports the study of Levy-Marchal. ${ }^{8}$ However, it may be due to the relatively small sample size. Therefore, further studies with longer study periods are required to confirm this hypothesis .

It is noteworthy that despite previous studies, the risk of DKA was not higher among patients $<5$ year old in the current study. ${ }^{24,25}$ Similar data has been reported by Lévy-Marchal and $\mathrm{Al}$ magami. ${ }^{8,19}$

In this study, two of cases, DKA was misdiagnosed as appendicitis. This indicates that when the diagnosis of acute abdomen is suspected, an attempt should be made to consider DKA in differentiation among children. It is also recommended that all surgeons dealing with acute abdomen conditions in children have a high index of suspicion of DKA before laparatomy.

One of the limitations of this study was the small sample size. A larger study is being designed with a large sample size and 15 years of data collection.

\section{Conclusion}

The frequency of diabetic ketoacidosis in newly diagnosed Type 1 diabetic children was significant in this region of Iran. However, it is comparable to other parts of the developed countries and lower than other regions in Asia. In addition, it was observed that polydipsia, polyuria, weakness and fatigue were the most frequent clinical symptoms reported at diagnosis. Overall, there was no correlation between sex, age and duration of symptoms and presentation at DKA state.

\section{Acknowledgements}

The results in this article are from the thesis of medical doctoral of Ms. Baharee Khansari, therefore we wish to thank her for her efforts. Special thanks to Mr. Khosrow Mani Kashani for his assistance in statistical analysis of the results.

This study was performed by permission of Commitee of Ethics in Medical Research School of Medicine/Hamadan University of Medical Sciences. No conflict of interest was reported and no funding was received.

\section{References}

1. Dunger DB, Sperling MA, Acerini CL, Bohn DJ, Daneman D, Danne TP, et al; ESPE; LWPES. ESPE/LWPES consensus statement on diabetic ketoacidosis in children and adolescents. Arch Dis Child 2004 Feb;89(2):188194.

2. Umpierrez GE, Kitabchi AE. Diabetic ketoacidosis: risk factors and management strategies. Treat Endocrinol 2003;2(2):95-108. 
3. Neu A, Willasch A, Ehehalt S, Hub R, Ranke MB; DIARY Group BadenWuerttemberg. Ketoacidosis at onset of type 1 diabetes mellitus in childrenfrequency and clinical presentation. Pediatr Diabetes 2003 Jun;4(2):77-81.

4. SWIFT PGF, ed. ISPAD Consensus Guidelines 2000. Medical Forum International, Zeist 2000.

5. Inward CD, Chambers TL. Fluid management in diabetic ketoacidosis. Arch Dis Child 2002 Jun;86(6):443-444.

6. Piva JP, Czepielewski M, Garcia PC, Machado D. Current perspectives for treating children with diabetic ketoacidosis. J Pediatr 2007;83:119-127.

7. Edge JA, Ford-Adams ME, Dunger DB. Causes of death in children with insulin dependent diabetes 1990-96. Arch Dis Child 1999 Oct;81(4):318323.

8. Lévy-Marchal C, Patterson CC, Green A; EURODIAB ACE Study Group. Europe and Diabetes. Geographical variation of presentation at diagnosis of type I diabetes in children: the EURODIAB study. European and Dibetes. Diabetologia 2001 Oct;44(Suppl 3):B75-B80.

9. Komulainen J, Lounamaa R, Knip M, Kaprio EA, Akerblom HK; Childhood Diabetes in Finland Study Group. Ketoacidosis at the diagnosis of type 1 (insulin dependent) diabetes mellitus is related to poor residual beta cell function. Arch Dis Child 1996 Nov; 75(5):410-415.

10. Hanas R, Lindgren F, Lindblad B. Diabetic ketoacidosis and cerebral oedema in Sweden-a 2-year paediatric population study. Diabet Med 2007 Oct;24(10):1080-1085.

11. Rewers A, Klingensmith G, Davis C, et al. Diabetic ketoacidosis at onset of diabetes: the SEARCH for Diabetes in Youth Study (Abstract). Diabetes 2008;121:1258-1266.

12. Bui TP, Werther GA, Cameron FJ. Trends in diabetic ketoacidosis in childhood and adolescence: a 15-yr experience. Pediatr Diabetes 2002 Jun;3(2):82-88.

13. Roche EF, Menon A, Gill D, Hoey H. Clinical presentation of type 1 diabetes. Pediatr Diabetes 2005 Jun;6(2):75-78.

14. Maldonado MR, Chong ER, Oehl MA, Balasubramanyam A. Economic impact of diabetic ketoacidosis in a multiethnic indigent population: analysis of costs based on the precipitating cause. Diabetes Care 2003 Apr;26(4):12651269.

15. Maniatis AK, Goehrig SH, Gao D, Rewers A, Walravens P, Klingensmith GJ. Increased incidence and severity of diabetic ketoacidosis among uninsured children with newly diagnosed type 1 diabetes mellitus. Pediatr Diabetes 2005 Jun;6(2):79-83.
16. Jasiński D, Pilecki O, Robak-Kontna K, Zbikowska-Bojko M. Analysis of type 1 diabetes mellitus symptoms at admission to hospital. Endokrynol Diabetol Chor Przemiany Materii Wieku Rozw 2003;9(2):83-87. medline.

17. Alvi NS, Davies P, Kirk JM, Shaw NJ. Diabetic ketoacidosis in Asian children. Arch Dis Child 2001 Jul;85(1):60-61.

18. Habib HS. Frequency and clinical characteristics of ketoacidosis at onset of childhood type 1 diabetes mellitus in Northwest Saudi Arabia. Saudi Med J 2005 Dec;26(12):1936-1939.

19. Al-Magamsi MS, Habib HS. Clinical presentation of childhood type 1 diabetes mellitus in the Al-Madina region of Saudi Arabia. Pediatr Diabetes 2004 Jun;5(2):95-98.

20. Ting WH, Huang CY, Lo FS, Hung CM, Chan CJ, Li HJ, et al. Clinical and laboratory characteristics of type 1 diabetes in children and adolescents: experience from a medical center. Acta Paediatr Taiwan 2007 MayJun;48(3):119-124.

21. al Khawari M, Shaltout A, Qabazard M, Abdella N, al Moemen J, alMazidi Z, et al; Kuwait Diabetes Study Group. Incidence and severity of ketoacidosis in childhood-onset diabetes in Kuwait. Diabetes Res Clin Pract 1997 Mar;35(2-3):123-128.

22. Lo FS, Yang MH, Chang LY, Ou YC, Van YH. Clinical features of type 1 diabetic children at initial diagnosis. Acta Paediatr Taiwan 2004 JulAug;45(4):218-223.

23. Imagawa A, Hanafusa T, Miyagawa J, Matsuzawa Y; Osaka IDDM Study Group. A novel subtype of type 1 diabetes mellitus characterized by a rapid onset and an absence of diabetes-related antibodies. N Engl J Med 2000 Feb;342(5):301-307.

24. Rosenbauer J, Icks A, Giani G. Clinical characteristics and predictors of severe ketoacidosis at onset of type 1 diabetes mellitus in children in a North Rhine-Westphalian region, Germany. J Pediatr Endocrinol Metab 2002 SepOct;15(8):1137-1145.

25. Rewers A, Chase HP, Mackenzie T, Walravens P, Roback M, Rewers M, et al. Predictors of acute complications in children with type 1 diabetes. JAMA 2002 May;287(19):2511-2518. 